\title{
Micromechanical modeling of polycrystalline high manganese austenitic steel subjected to abrasive contact
}

\author{
Matti LINDROOS*, Anssi LAUKKANEN, Tom ANDERSSON \\ VTT Lifecycle Solutions, Tampere 33720, Finland \\ Received: 21 March 2018 / Revised: 17 April 2018 / Accepted: 4 July 2019 \\ (C) The author(s) 2019.
}

\begin{abstract}
This study focuses on microstructural and micromechanical modeling of abrasive sliding contacts of wear-resistant Hadfield steel. 3D finite element representation of the microstructure was employed with a crystal plasticity model including dislocation slip, deformation twinning, and their interactions. The results showed that deformation twinning interacting with dislocations had a key role in the surface hardening of the material, and it was also important for the early hardening process of the sub-surface grains beyond the heavily distorted surface grains. The effects of grain orientation and microstructural features were discussed and analyzed according to the micromechanical model to give a perspective to the anisotropy of the material and the feasibility of using micromechanics in virtual material design.
\end{abstract}

Keywords: crystal plasticity; micromechanical modeling of abrasion; austenitic manganese steel; deformation twinning

\section{Introduction}

High manganese austenitic steels are favored for many applications facing high-stress abrasion and high energy impact loads [1-5]. Such conditions can be found in various applications in the mining industry, such as during rock crushing in a mineral crusher. The material's capability of extraordinary strain hardening combined with excellent ductility provides a suitable combination for situations in which the surface is loaded with extreme strains. As a result, high manganese austenitic steels are wear-resistant steel grade often favored for the most extreme abrasive wear conditions.

High manganese austenitic steels, commonly known as Hadfield steels can tolerate high strain states by the activation of deformation twinning in addition to dislocation slip. Another characteristic is the additional deformation mode, involving the interaction of the deformation mechanisms. In this mode, the twin boundaries often subdivide large austenitic grains into smaller sub-grains, contributing to the strong strain hardening of the material. The twin boundaries act as effective barriers against dislocations, cause dislocation pile-ups, and reduce the mean free path of the dislocations, effectively hardening the material. There are other contributors to the excellent strain hardening capability, such as the formation of dislocation walls $[6,7]$ and dynamic strain aging (DSA) of Mn-C couples [8-10]. Furthermore, the material is strain-ratedependent due to the face-centered cubic (FCC) crystal structure. It may exhibit positive or even DSA-driven negative strain rate dependency at low strain rates in some compositions [11, 12]. Dynamic strain rates experienced in impact conditions usually generate a positive strain rate dependency that increases material's flow stress. From the wear point of view, an increase in deformation resistance at high strain rates can have a positive influence on impact resistance when the material remains ductile.

Many excellent experimental studies have focused on revealing the deformation, hardening, and failure

* Corresponding author: Matti LINDROOS, E-mail: matti.lindroos@vtt.fi 
mechanisms of high manganese austenitic steels [8, 13-17]. Simulation approaches aim to capture these phenomena in numerical constituents that represent the prevailing physics with a certain degree of simplification. Among the modeling approaches for Hadfield steels, Karaman et al. [18] have focused on the single and polycrystal behavior of the material and also on the grain size effect using a self-consistent crystal plasticity model. Their experimental results show a reasonable agreement with the model, but the studies lack an explicit definition of the microstructure. In turn, Lindroos et al. [19, 20] have studied the behavior of different grain structures with discretized microstructures, providing more information about local effects. Canadinc et al. [7, 21] have focused their efforts on numerically studying the effects of nitrogen and aluminum alloying in the material, to seek alternative compositions for improved mechanical behavior. Impact-related experimental study of Toker et al. [22] and Gumus et al. [23, 24], and numerical modeling of Onal et al. [10] have revealed that strong strain hardening of the Hadfield material is caused by the formation of nano-twins and their interaction with gliding dislocations, with a marked dependency on temperature and strain rate. The crystal plasticity simulations of Lindroos et al. [25] have provided some insight into the behavior of Hadfield steel polycrystal microstructures under impact loading and its influence on wear behavior. Dynamic strain aging has been included in the modeling approach by Bal et al. [26] to capture its influence on the hardening behavior of the conventional Hadfield steel grade (i.e., $10 \%-14 \%$ Mn and $1.0 \%-1.4 \%$ C). Multiscale linking operation of using the information of a crystal plasticity model at macroscopic scale simulations has also been favored to widen the usability of small scale models of Hadfield steels [27, 28].

Multiscale modeling of tribological contacts is a growing field of interest. It can provide a fundamental understanding of contact situations and stresses [29]. Wear and failure predictions can be made according to experimental and modeling studies [30]. In terms of abrasion and impacts, the models often involve the definition of the contacting particles and the deforming or wearing material with a special interest in its material modeling. Due to the complicated nature of the tribological contacts, it is often accepted that either the particles or the counter-surface material definitions undergo some levels of simplification. Particles can have complex shapes when they are a matter of interest in Ref. [31]. In contrast, the counter-surface material studied can have a very detailed model about its mechanical behavior [18]. Successful integration of detailed arbitrary shaped particles and highly non-linear behavior of the counterface materials has been achieved [28]. The ultimate aim of the modeling is to increase understanding of the prevailing deformation and/or wear phenomena.

Despite large interest in using steel materials as wear-resistant parts in various applications, polycrystalline materials have received less attention when a detailed microstructure based model is involved. A joint description of microstructure and crystal plasticitybased constitutive models is very limited when tribological contacts are considered. Understanding the deformation behavior of polycrystalline material at the single indentation level is already quite challenging and may require a decent amount of experimental verification, as shown by Sabnis et al. [32] and Gao et al. [33]. Nicola et al. [34] have analyzed the deformation response of two different crystal plasticity formulations in a simple indentation procedure. Musinski et al. [35] have coupled crystal plasticity and shot peening loads by a load transfer technique to estimate the effect of surface residual stresses. Recently, Rousseau et al. [36] have studied the normal direction impacts on a polycrystalline material and analyzed deformation and hardening behavior with a crystal plasticity model involving contacts. Rough contacting surfaces have been studied to reveal local deformation and contact behavior by making use of crystal plasticity formulation [37, 38]. However, these models are mainly scoped to only relatively small deformations and very limited sliding. To the knowledge of the authors of the present report, no studies have focused on high-stress abrasion with sliding particle contact on polycrystalline materials.

Thus, the main objective and novelty of this study are to establish a micromechanical model of high-stress abrasion. The high-stress abrasive contact is simplified to indenter-polycrystal interaction and deformation. In detail, the modeling approach includes a microstructural model and a sliding abrasive on the surface that generates large deformations and plasticity, which 
often precede material removal (wear). The second objective is to analyze the deformation and hardening behavior of a polycrystalline Hadfield steel material under abrasive conditions in order to capture similarities between field- and laboratory-tested samples. Another novelty of this study is the evaluation of the capabilities of a complex crystal plasticity model for one type of tribological contact analyses. A crystal plasticity model including dislocation slip and deformation twinning was used to describe the complex deformation behavior occurring in a Hadfield steel grade. The first simulation case focused on the stress and strain evolution related to the deformation of the microstructure, and on the twin propensity around the scratch region. The second simulation case provides information about the tensioncompression asymmetry of the Hadfield steel in a contact-induced complex stress state to evaluate its importance in tribological contacts. A discussion summarizing of microstructure-based observations and experimental observations is provided.

\section{Experimental details}

\subsection{Material and application}

The material is high manganese austenitic steel, commonly known as the Hadfield steel. A nominal composition consists of $16.5 \mathrm{wt} \% \mathrm{Mn}, 1.05 \mathrm{wt} \% \mathrm{C}$, $1.8 \mathrm{wt} \% \mathrm{Cr}$, small quantities of aluminum and molybdenum, and Fe-balance. The microstructure is metastable austenitic at room temperature, and the material was cast and annealed. The grain size varied generally between 200 and $800 \mu \mathrm{m}$, and it occasionally was even larger depending on the cast section thickness. The macroscopic as-cast hardness of the material was 250-300 HV.

The material is typically used in mining industry applications such as in the wearable jaw parts of a jaw crusher used in mineral crushing. In such conditions, the material is expected to withstand high-stress abrasion during the crushing stage of the rocks and endure impact loadings at the same time. A more detailed description of the material application and its behavior under prescribed conditions is provided in Ref. [36].

\subsection{Numerical model}

The present study focused on the modeling of abrasive conditions for the material by utilizing a micromechanics approach. A scratch test definition was chosen as descriptive in order to simplify the contact conditions of realistic rocks. Rocks may be used in a scratch test environment, but their breakage continuously changes the contact dynamics [38], thus they are not the best choice for a preliminary crystal plasticity study. Therefore, the model consisted of a diamond Rockwell-C scratch stylus with a radius of $200 \mu \mathrm{m}$ and a synthetic representative volume element (RVE) of polycrystalline Hadfield steel. The grain size of the modeled steel resembled the grain size of the cast material with a nominal size variation between 200 and $800 \mu \mathrm{m}$. Figure 1 shows the model assembly and the used polycrystal mesh for the modeling. Mesh density was chosen to be medium coarse in order to retain the computational efficiency of the crystal plasticity model in contact conditions. A total of 150 grains were included in the RVE discretized with a total of 1658792 C3D4 linear tetrahedron elements. The size of the RVE was $1.5 \mathrm{~mm} \times 0.7 \mathrm{~mm} \times 0.5 \mathrm{~mm}$. Displacement boundary conditions were applied to the external faces of the RVE, excluding the contact face, to avoid external deformation of the RVE.

Two cases were investigated. Case I in Fig. 1(a) was used to reveal deformation and hardening behavior of the material when the orientation distribution was random, as typical for a cast material. Case II concentrated on the effect of specific single-crystal orientations of the material, which had fairly strong tension-compression asymmetry. The pre-scribed orientations in the scratch path are shown in Fig. 1(b). Bal et al. [26] have experimentally analyzed the deformation mechanisms in these orientations. Orientation [001] has a tendency to twin predominated deformation in uniaxial compression and multiple slip predominated deformation in tension. Orientation [111] mainly deforms by a slip in compression and strong pre-dominance of multiple twin systems occurs in tension. Orientation [123] first deforms by a single slip system followed by activation of a multiple slip system when deformation progresses, in both tension and compression.

The crystal plasticity model was implemented in Z-set (Zébulon) and used in Abaqus/Standard FE-solver via ZMAT-interface. The diamond indenter was considered elastically deformable with a Young's modulus 


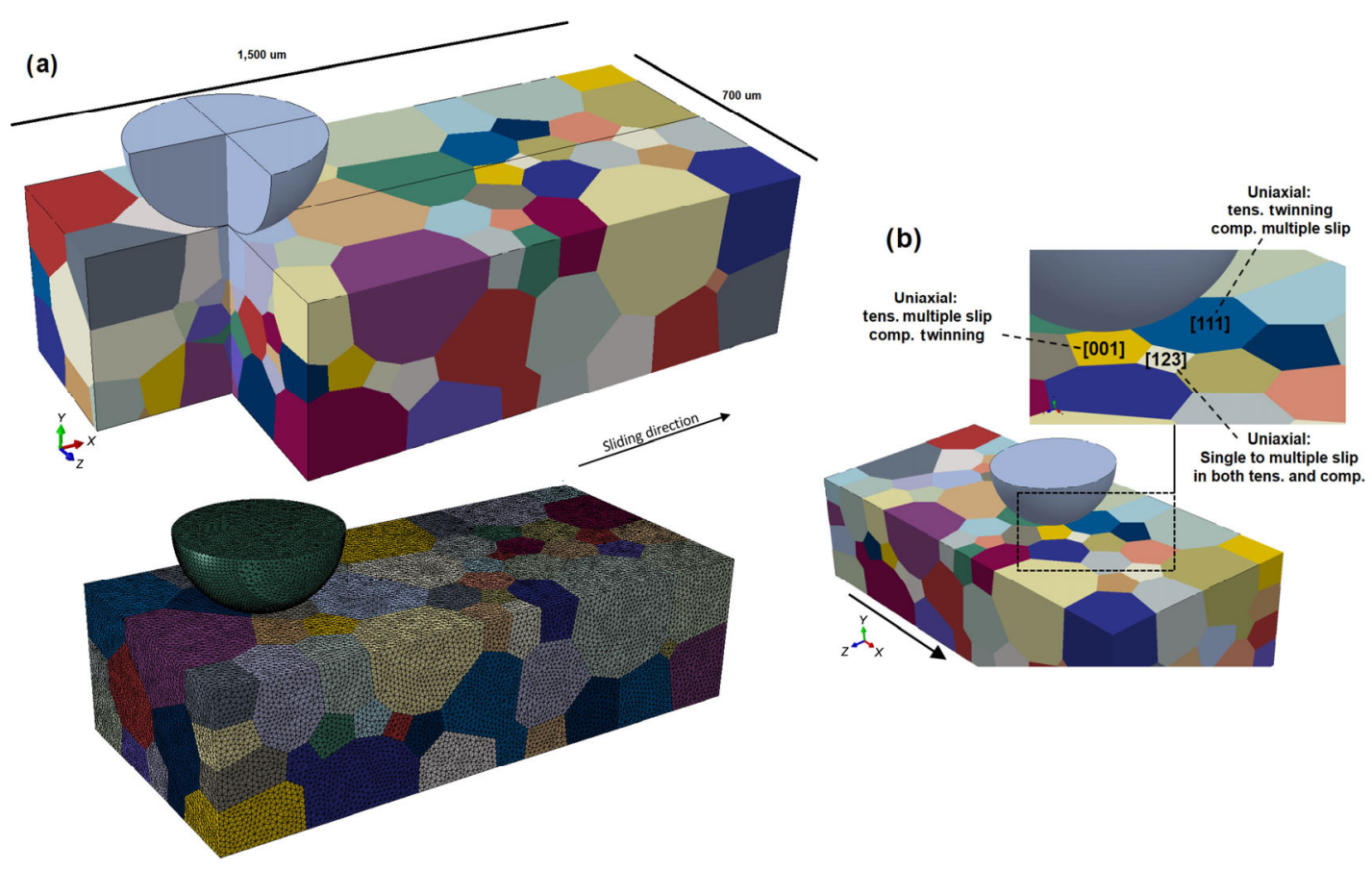

Fig. 1 (a) Sliding abrasive on a polycrystalline austenitic high manganese steel material (case I) and (b) specific single-crystal orientations selected into the scratch path (case II).

of 1,140 GPa and 0.07 Poisson's ratio [30]. Both surfaces were considered ideally smooth. The sliding velocity was set to constant $0.1 \mathrm{~mm} / \mathrm{s}$ in the simulations. Coulomb-type of coefficient of friction was adopted for simplicity, with a constant value for the material pair equals to 0.19 . The value corresponded to the average of $40 \mathrm{~N}$ loading cases in a scratch test experiment performed for the material [39]. The contact between the indenter and polycrystalline material was discretized with surface-to-surface contact. Penalty method was used for contact identification. The finite sliding formulation was utilized.

Sliding contact was modeled by generating movement to the diamond stylus. The penetration of the sliding indenter was displacement-controlled with increasing displacement amplitudes.

The penetration during sliding reached 7.0 and $6.0 \mu \mathrm{m}$ for Case I and Case II, respectively. The scratch experiments with diamond stylus and natural granite rock tip showed that this surface deformation could be considered as a high-stress abrasion condition [40]. For example, granite rock tip caused local surface deformation of $2-8 \mu \mathrm{m}$ on high strength steel in a scratch test with a high probability of rock breakage during the test, suggesting one limiting value for sharp rock high-stress abrasion [40]. The simulations were performed on as-cast material with no pre-existing deformation and without any residual stress for the sake of simplicity.

\subsection{Crystal plasticity model}

A rate-dependent crystal plasticity model is used to describe the deformation behavior of the polycrystalline material. The plastic deformation of the material is carried over by dislocation slip and deformation twinning. The model behavior has been analyzed and verified in Ref. [19], and applied to studies of the effects of grain structure [20] and strain rate [25]. However, these studies focus on the deformation of RVEs and exclude the direct definition of complex stress states.

Deformation gradient is multiplicatively composed of the elastic and plastic parts as $\underline{F}=\underline{F}^{E} \underline{F}^{P}$. The plastic velocity gradient can be reformulated to include the contributions from both dislocation slip and twinning [23] as follows:

$$
\underline{\dot{\varepsilon}}^{p}=\left(1-\sum_{\beta=1}^{n_{\beta}} f^{\beta}\right) \sum_{s=1}^{n_{s}} \dot{\gamma}^{s} \underline{N}^{s}+\sum_{\beta=1}^{n_{\beta}} f^{\beta} \gamma^{\mathrm{tw}} \underline{N}^{t}
$$


where $\dot{\gamma}^{s}$ is the shear rate of a slip system $s, f^{\beta}$ is the twin volume content of the twin system $\beta \cdot \gamma^{\text {tw }}$ is the constant shear strain associated with twinning. The orientation tensors for individual slip systems and twin systems are constructed of the slip/twin plane normal $\underline{n}^{s}$ and slip/twin direction $\underline{m}^{s}$, by $\underline{N}^{s}=\underline{m}^{s} \otimes \underline{n}^{s}$. The number of possibly active slip and twin systems is described by the parameters $n^{s}$ and $n^{\beta}$. In the present model, twins are presented by the twin volume fraction $f^{\beta}$, to avoid an explicit definition of initiating and growing twins. A total of 12 potential $\{111\}<110>$ slip systems in the matrix and 12 potential $\{111\}<11 \overline{2}>$ twin systems operating in the untwinned parts of the crystal are considered in the model.

The current study employed the model framework and parametrization presented in previous studies $[19,20,25]$. Thus, the model details, such as slip/twin interactions and hardening descriptions, were not reproduced in the present context. The shear rate of a slip system was defined as

$$
\dot{\gamma}^{s}=\left(\frac{\left|\tau^{s}\right|-r^{s}-\tau_{0}^{s}}{K}\right)^{n} \operatorname{sign} \tau^{s}=\dot{v}^{s} \operatorname{sign} \tau^{s}
$$

where $\tau^{s}$ is the resolved shear stress on a system $s$, $\tau_{0}$ is the initial shear resistance of as-cast material, and $\gamma^{s}$ is the isotropic hardening variable; parameters $K$ and $n$ characterize the viscosity. The model employed the Mandel stress definition $\underline{M}$ and the resolved shear stress of a slip system $s$ was computed in Eq. (3):

$$
\tau^{s}=\underline{M}: \underline{N}^{s}=\left(\underline{C}^{e} \cdot \underline{S}^{e}\right): \underline{N}^{s}=\left(\underline{C} \cdot\left(\underline{\Lambda}: \underline{E}_{g 1}\right)\right): \underline{N}^{s}
$$

where $\underline{S}^{e}$ presents second Piola-Kirchhoff stress, while $\underline{C}^{e}$ is the Cauchy-Green tensor, $\underline{\Lambda}$ denotes elastic stiffness tensor, and $\underline{E}_{\mathrm{gl}}$ is the Green-Lagrange strain tensor.

Two ideally separate sources harden a slip system $s$ : the hardening originating from slip-slip interactions and the hardening caused by the barrier effect of twin-slip interactions. These two contributions were included with the hardening variable $r^{s}$.

$$
r^{s}=r_{\mathrm{sl} \rightarrow \mathrm{sl}}^{s}+r_{\mathrm{tw} \rightarrow \mathrm{sl}}^{s}
$$

Accumulated slip of different slip systems drives the slip-slip interaction term that controls the isotropic slip-hardening part.

$$
r_{\mathrm{sl} \rightarrow \mathrm{sl}}^{s}=Q \sum_{r} H_{r s}\left[1-\exp \left(-b v^{r}\right)\right]
$$

where $v^{r}$ accounts for the cumulative slip in a system $r$. Parameters $Q$ and $b$ characterize the intensity of the hardening and its saturation, respectively. The different types of dislocation interactions are included through the interaction matrix $H_{r s}$, containing the self (diagonal) and latent hardening (non-diagonal terms). The individual parameters of the hardening matrix were ordered according to the one suggested by Franciosi [41] with 144 slip interactions between the slip systems. Altogether, the final number of the interactions is decreased to six independent parameters in the FCC crystal according to this interaction formulation.

A generalized form of the twin-slip hardening phenomenon was adopted by considering effective grain size reduction deriving from the increase in the twin volume fraction [42] (i.e., the twin volume fraction was assumed to be inversely proportional to the average spacing of the twins, meaning that the grain size decreases when the twin volume fraction increases). Therefore, the hardening rule presents the collective effect of existing deformation twins in an average sense, and no explicit definition of twins is included in the finite element mesh. This assumption simplifies the actual physics to a certain degree to remove direct mesh size dependency of the initiating and growing twins. The twin-slip hardening rate is given by

$$
\dot{r}_{\mathrm{tw} \rightarrow \mathrm{sl}}^{\mathrm{s}}=0.5 H_{\mathrm{tw}}^{\mathrm{sl}}\left(\sum_{\text {Non-coplanar }}^{n_{\beta}} f^{\beta}\right)^{-0.5} \dot{f}^{\beta}
$$

where $H_{\mathrm{tw}}^{\mathrm{sl}}$ characterizes the intensity of the hardening, and the exponent 0.5 was adopted from the ideal HallPetch relation (i.e., dynamic grain size refinement as a function of twin volume fraction). The hardening is caused only by the non-coplanar twins acting as barriers for dislocations and causing dislocation pile-ups.

The competition between dislocation slip and deformation twinning is also affected by strain rate through the thermally activated dislocation motion and various dislocation drag mechanisms. Deformation twinning has generally been found to be less sensitive to the strain rate than slip. However, the initiation and growth 
rate of twinning can be increased when the dislocation slip becomes more difficult at very high strain rates. In order to avoid the treatment of the complex and largely controversial kinetics of the twin initiation and growth, the same rate-dependent Norton formulation was chosen for twinning as for dislocation slip. The generalized viscoplastic formulation for twinning also allows controlling the balance between twinning and dislocation slip as a function of strain rate whenever required. Twinning was assumed to be triggered when a threshold value of the critical twinning stress was exceeded with the criterion based on the Schmid type behavior. The flow rule is therefore written as follows:

$$
\dot{f}^{\beta}=k_{c}\left(f_{\max }-\sum_{\beta=1}^{n_{\beta}} f^{\beta}\right)\left(\frac{\left|\tau^{\beta}\right|-r^{\mathrm{tw}}-\tau_{0}^{\mathrm{tw}}}{K_{t}}\right)^{n_{t}}
$$

where a simple parameter $k_{c}$ controls the magnitude of twinning, parameter $f_{\max }$ restricts the maximum total twin volume fraction of all systems, $\tau^{\beta}$ is the resolved shear stress acting on twin system $\beta, \tau_{0}^{t w}$ is the initial critical twinning stress, $r^{\text {tw }}$ is the isotropic hardening for twinning, and $K_{t}$ and $n_{t}$ describe viscous behavior of twinning. No particular constraint was placed on the maximum twin volume fraction of each individual twin system in the present context. This allows the material to exhibit strong pre-dominance of individual twin systems whenever required (i.e., one twin system can dominate until saturation with only minor activity in secondary systems).

The internal hardening variable $r^{\text {tw }}$ accounts for the effects of twin-twin interaction and slip-twin interaction separately.

$$
r^{\mathrm{tw}}=r_{\mathrm{tw} \rightarrow \mathrm{tw}}^{\mathrm{tw}}+r_{\mathrm{sl} \rightarrow \mathrm{tw}}^{\mathrm{tw}}
$$

The twin-twin contribution was modified from the expression of Kalidindi [42], according to which both the non-coplanar and co-planar twins can cause the material different levels of hardening.

$$
\begin{aligned}
\dot{r}_{\mathrm{tw} \rightarrow \mathrm{tw}} & =H_{\mathrm{nc}}^{\mathrm{tw}}\left(\sum_{\beta=1}^{n_{\beta}} f^{\beta}\right)^{b_{t}} \sum_{\text {Non-coplanar }}^{n_{\beta}} \gamma^{\mathrm{tw}} \dot{f}^{\beta} \\
& +H_{\mathrm{cp}}^{\mathrm{tw}}\left(\sum_{\beta=1}^{n_{\beta}}\right)^{g} \sum_{\text {Co-planar }}^{n_{\beta}} \gamma^{\mathrm{tw}} \dot{f}^{\beta}
\end{aligned}
$$

$H_{\mathrm{nc}}^{\mathrm{tw}}$ and $H_{\mathrm{cp}}^{\mathrm{tw}}$ are the parameters controlling the magnitude of hardening for non-coplanar and coplanar twins, respectively. The two exponents $b_{t}$ and $g$ characterize the effectiveness of the hardening with the evolving non-coplanar and co-planar twin volume fractions.

It is considered that high dislocation density in the matrix regions can cause effective hardening against the twins [19], simply by suppressing twin nucleation and growth (e.g., by rendering the conditions unfavorable for twin nucleation). A collective hardening effect suggested by Salem et al. [43] was incorporated to account for the increasing resistance against twinning when slip accumulated in the matrix.

$$
\dot{r}_{\mathrm{sl} \rightarrow \mathrm{tw}}^{\mathrm{tw}}=H_{\mathrm{sl}}^{\mathrm{tw}}\left(\sum_{s=1}^{n_{s}} v^{s}\right)_{s=1}^{d} \sum_{s}^{n_{s}} \dot{v}^{s}
$$

where parameter $H_{s l}^{t w}$ characterizes the magnitude of the hardening. The exponent $d$ defines the shape of the curvature concentrating the hardening either to the early or later stages of the deformation.

The crystal plasticity model parameters were identified in Ref. [19] for the studied Hadfield steel and are listed in Table 1.

Table 1 Model parameters for the 16.5\% Mn, 1.05\% C Hadfield steel, Reproduced from Ref. [19].

\begin{tabular}{ccc}
\hline Parameter & Value & Unit \\
\hline Elastic constant & 174,000 & $\mathrm{MPa}$ \\
$C_{11}$ & 85,000 & $\mathrm{MPa}$ \\
$C_{12}$ & 99,000 & $\mathrm{MPa}$ \\
$C_{44}$ & & \\
\hline Slip parameter & 91.0 & $\mathrm{MPa}$ \\
$\tau_{0}^{s}$ & 91.0 & $\mathrm{MPa} \cdot \mathrm{s}^{1 / n}$ \\
$K$ & 14.0 & - \\
$n$ & 2.35 & - \\
$b$ & 180.0 & $\mathrm{MPa}$ \\
$Q$ & 0.12 & - \\
$h_{0}$ & 0.10 & - \\
$h_{1}$ & 1.60 & - \\
$h_{2}$ & 1.85 & - \\
$h_{3}$ & 0.36 & - \\
$h_{4}$ & 0.80 & - \\
$h_{5}$ & & - \\
\hline Twin parameter & $1 \mathrm{e}^{-5}$ & \\
$K c$ & & \\
\hline
\end{tabular}


(Continued)

\begin{tabular}{ccc}
\hline Parameter & Value & Unit \\
\hline$\tau_{0}^{\mathrm{tw}}$ & 98.0 & $\mathrm{MPa}$ \\
$K_{t}$ & 98.0 & $\mathrm{MPa} \cdot \mathrm{s}^{1 / n}$ \\
$n_{t}$ & 30.0 & - \\
$H_{\mathrm{tw}}^{\mathrm{sl}}$ & 170.0 & $\mathrm{MPa}$ \\
$H_{\mathrm{nc}}^{\mathrm{tw}}$ & 650.0 & $\mathrm{MPa}$ \\
$H_{\mathrm{cp}}^{\mathrm{tw}}$ & $1,550.0$ & $\mathrm{MPa}$ \\
$H_{\mathrm{sl}}^{\mathrm{tw}}$ & 550.0 & $\mathrm{MPa}$ \\
$b_{t}$ & 0.3 & - \\
$g$ & 0.9 & - \\
$d$ & 1.3 & - \\
\hline
\end{tabular}

\section{Simulation results}

Figure 2 shows equivalent and the 1st principal stress contours plotted on the microstructure for both investigated cases. The equivalent stresses appeared high, usually between 1,200 and 1,500 MPa, close to the surface (red color), arising from the hardening of the material. The distribution of the stress was fairly similar to typical continuum stress distribution of sliding contact in an average sense. However, the stress variations existed among the grains, and stress concentrations could build up close to the grain boundaries and inside the grains. The grain boundaries experienced elevated stress depending on the grain-grain interaction and local accumulation of slip and twins in line with the previous studies $[19,20,25]$. The intra-grain variations obviously depended on the increasing penetration of the abrading particle (stylus), but also on the local evolution of deformation twins (Fig. 3). Over $700 \mathrm{MPa}$ stress (green color in the contours) was observed over a depth of few grains in the sub-surface region. This stress was sufficient to initiate slip and twinning, which hardened the interior of the material.

The 1st principal stress contours in Figs. 2(b) and 2(d) show the distribution of the principal stress state under sliding contact in a polycrystal material. Compressive stresses were observed in front of and under the contact (blue color), as the stress was negative in these regions. The trailing edge of the contact and the region behind the sliding stylus exhibited a state of strong tensile stress, easily exceeding 1,500 MPa near the surface. The sub-surface region was under compression of the heavily deformed surface layer. In contrast to a more general view on the stress state, the intensity of the 1st principal stresses varied depending on the grain structure (morphology and size) and neighboring effect by the orientation of the grains (Fig. 2(d)).

Figure 3(a) shows the cumulative plastic strain contributed by dislocation slip and deformation. The
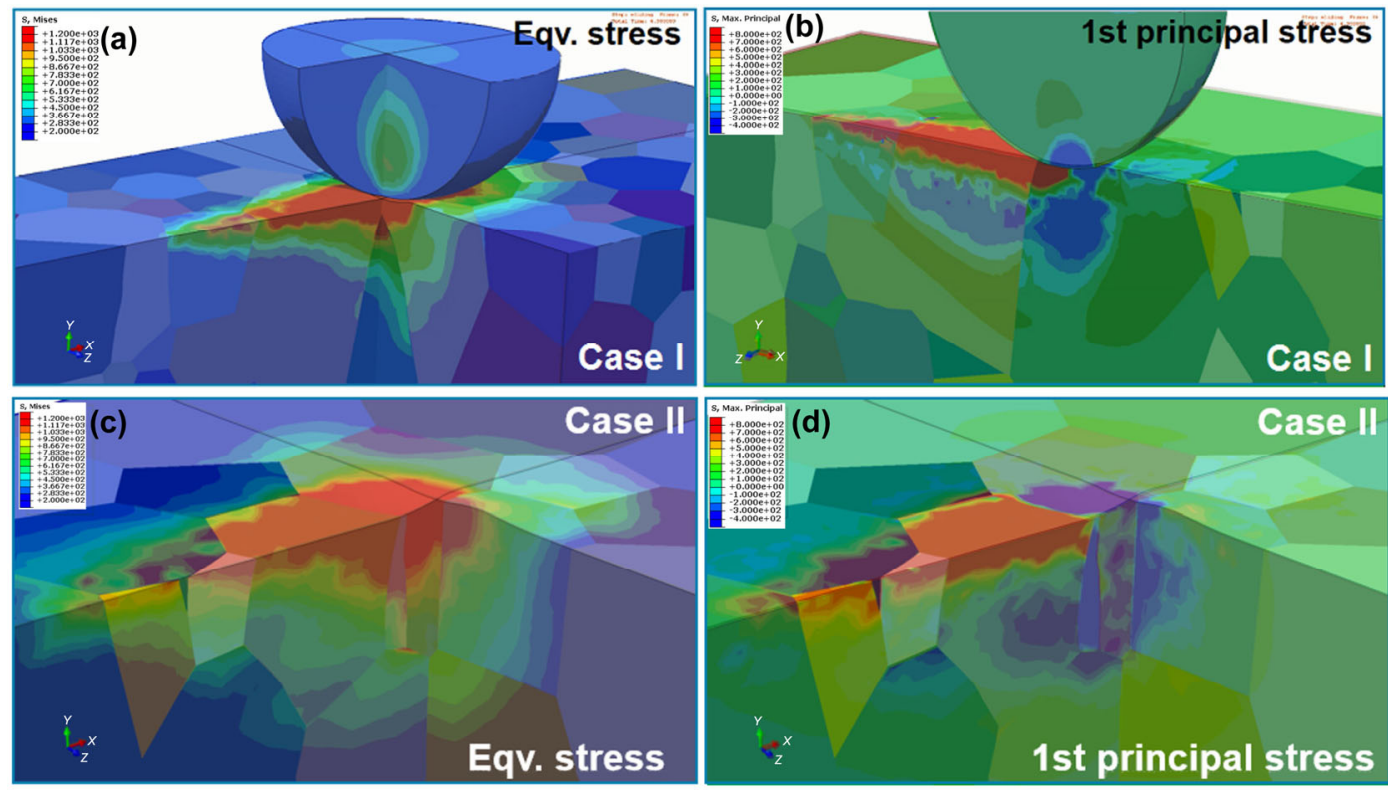

Fig. 2 Equivalent stress: (a) and (c) with the legend contour limited to max 1,200 and min $200 \mathrm{MPa}$ and the 1st principal stress: (c) and (d) with the legend contour limited to max 800 and $\min -400 \mathrm{MPa}$ during scratching for Case I and II. 

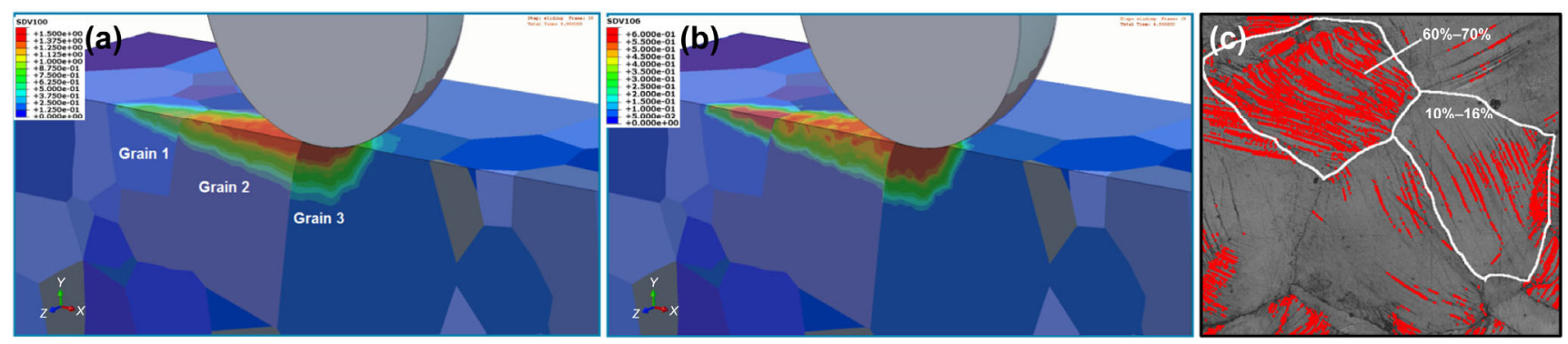

Fig. 3 (a) Cumulative plastic strain contributed by slip and deformation twinning (red color is 1.5), (b) twin volume fraction (red color is 0.5 ), and (c) two twinned grains with the average twin volume fraction after a uniaxial compression test, reproduced from Ref. [34].

cumulative plastic deformation exceeded 150\% (red zones) on a quite thin layer on the surface, but notable plasticity also took place on the sub-surface, reaching $>50 \%$ of the cumulative plastic strain (green zones). The increasing penetration of the sliding stylus increased the in-depth extensiveness of the heavily deformed region.

Figure $3(b)$ shows that the volume fraction of the twins did not depend only on the increasing surface penetration but also strongly on the orientation of the grains. The red color in the contours represents twin volume fraction $>0.5$. For example, grain 1 showed a relatively high twin volume fraction near the surface already at lower penetration values of the indenting stylus in relative to grain 2. Grain 3 further showed the non-linear twin evolution with a notably intensive twin distribution deeper in the material. Large local variations in the twin volume fraction were observed within the heavily deformed region, from small (0.3) up to the saturation value of 0.85 . The highest values were found in the scratch bottom and near the grain boundaries. In general, the ploughed edge regions showed lower twin volume fractions than the ploughed region directly in front of the sliding stylus.

Figure 3(c) illustrates two grains with different amount of deformation twins after a uniaxial compression test. The volume fractions of deformation twins were identified with an image analysis based on the electron back-scatter diffraction (EBSD) measurement highlighting the $60 \pm 5$ degrees of misorientation around 111-planes [19]. To give a perspective, the heavily twinned grain could ideally correspond to the heavily deformed and twinned region near the surface, while the grain with a lower amount of twins could ideally correspond to the sub-surface region. It can be deduced from the sample analysis that even at low twin volume fractions, the existing twin boundaries can easily decrease the effective grain size and cause notable hardening of the material. EBSD measurements on the heavily deformed region are extremely challenging due to the heavy distortions, heavy slip banding, and dense deformation twinning at the surface, which can only be identified partially because of low indexing quality [25]. For identifying the underlying mechanisms, the results of the simulations provide additional information. For example, the simulations showed that multiple twin systems, such as 3-6 systems, were active in the scratch bottom region. The high number of twin systems generated an effective obstacle network within the grains.

Figure 4 shows the activity of the individual twin systems acting on different twin planes. Twin system 3 contributed more strongly to the overall twin volume fraction than system 6 . The contribution of twin system three concentrated on the scratch bottom and showed little activity at the ploughed edges of the scratch, where system 6 compensated and strongly contributed to twinning. The resolved shear stress, which is the driving force for twinning in the current model, showed the expected grain orientation dependency. It is worth noting that the resolved shear stress computed based on the grain orientations is not equal to the overall prevailing shear stress distribution of the contact, which followed a more typical distribution of sliding contact.

The formation of the twins in system 3 took place in the compressive region of the sliding contact, in front of and under the sliding stylus, where the resolved shear stress was positive. When analyzing grains 1 and 2, no post-contact twinning was observed at the trailing edge of the contact because of the negative resolved shear stress for this particular twin system, 

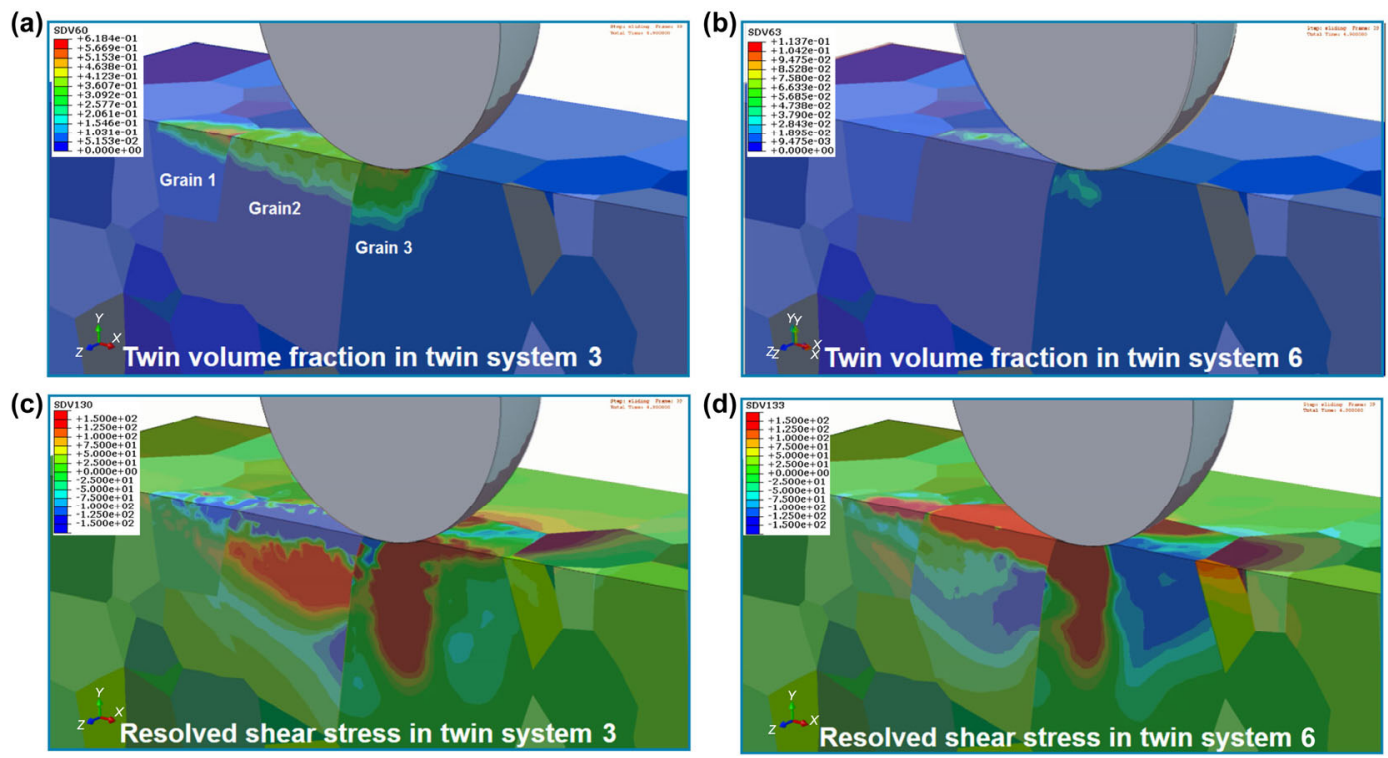

Fig. 4 Twin volume fraction and resolved shear stress in (a) twin system 3 and (b) twin system 6 for Case I. Red color in resolved shear stress denotes positive stress and blue color negative stress.

which cannot grow twins due to the polarity of FCC twinning (twinning takes place only in the positive direction). Twinning in twin system 6 could take place in the trailing region of the contact at the scratch bottom, but the hardening mainly deriving from twin system 3 suppressed its activity almost fully. In turn, grain 3 had a favorable orientation for both twin systems, and a contribution was seen from both systems.

The numerical results showed that the twin nucleation and growth depended on both the stress state induced by the abrading particles as well as the orientation. For example, it is noteworthy that despite the same initial grain orientation of grain 2, the twin activity was not equal in the scratch bottom and edge pile-up regions owing to the different stress states.

The simulation Case II focused on studying the orientation effect of the material in more detail. Figure 5 shows the simulation response for three specific orientations, [111], [001], and [123]. Figure 5(a) shows the assignment of the orientations and the deformation during the scratch simulation. The contour in-depth displacement (height and depth direction) illustrates the local grain dependent deformation response. Orientation [111] developed two times higher ploughed edge region than orientation [001].

One explanation for the observed behavior is that even though [111] is essentially a harder orientation than [001], notable twinning in [111] oriented grain first softened the deformation response before the strong hardening was observed at higher twin volume fractions. In turn, [001] oriented grain exhibited twinning only in the compressive region of the sliding contact whilst the volume fraction of the twins in the pile-up region was very small. This result also shows that despite the strong tension-compression asymmetry of [111], in terms of flow stress and deformation mechanism pre-dominance, the more complex triaxial stress state can easily promote twinning even if the principal stress state is either in compression (scratch bottom during contact) or tension (edge region). This locally observed behavior, however, did not always take place, as noted in the [001] oriented grain. It only exhibited twinning in the scratch bottom during the compressive stress stage of the contact, but only very limited or diminishable twinning deformation of the ploughed edge with tensile principal stress state. The single slip-dominated orientation [123] under uniaxial loading exhibited strong twinning during the scratch simulation. The twins were mostly formed during the compressive stage of the contact load, but the twin volume fraction increased slightly also after the contact.

In general, deformation twinning was less pronounced in the ploughed edge region, probably in a relation with smaller deformation than in the scratch 

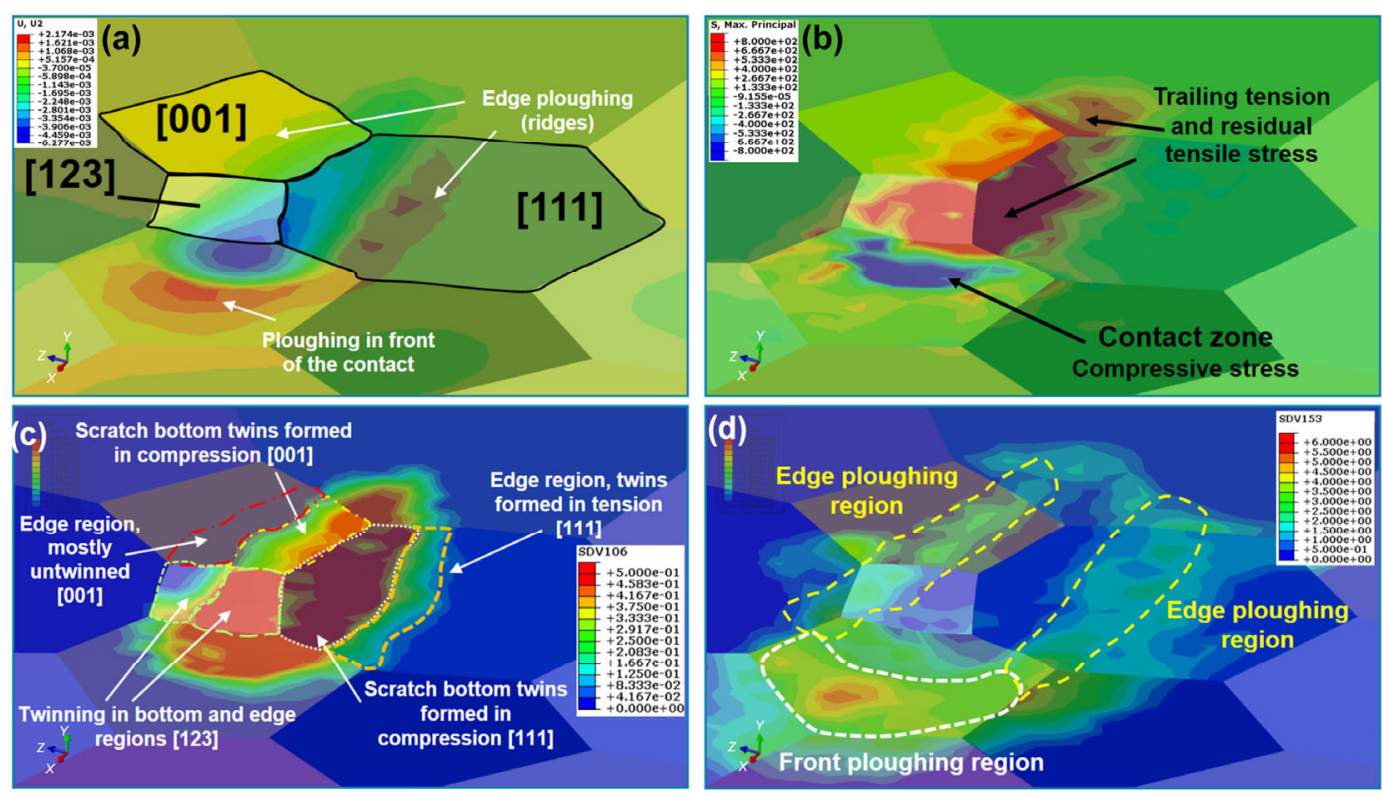

Fig. 5 (a) In-depth displacement during the simulation and specific orientations of the grains, (b) 1st principal stress contour, (c) twin volume fraction (red is 0.5 ), and (d) number of currently active twin systems (red is 6).

bottom region. The deformation was more slipcontrolled.

For example, the twin volume fractions at the edge regions usually remained between 0.1 and 0.3 , while the scratch bottom experienced a high amount of twinning, such as $0.5-0.85$, as noted above.

One aspect affecting the twin propensity of all orientations is that the ploughing taking place in front of the sliding stylus generates plasticity by both dislocation slip and twinning. The reorientation generated by slip deformation can also reorient the grain towards more favorable twin orientation. Figure 5(d) shows the number of active twin systems during the scratch simulation. It can be seen that saturation took place in the scratch bottom behind the sliding stylus, but other areas tended to be still active. Especially, a relatively high number of twin systems (4-6 systems) were active in front of the stylus at the ploughed region, generating microtwinning in this region. This may have happened due to the sheer magnitude of the plasticity and high stress prevailing in the region but the reorientation effect of slip deformation may have also contributed. The ploughed edge regions usually show a lower number of active twin systems, such as 3 in most cases or 4 occasionally. No distinctive difference was observed in the number of the active slip systems, usually, 2 to 8 were active in the regions with notable plasticity.

The deformation of the two scratch simulations is shown in Fig. 6. The deformation was up-scaled by a factor of 5 for illustrative purposes. In both cases, it is clear that the microstructure affected the local deformation response. Especially Case II showed a very distinctive formation of localized ploughing in one grain in front of the sliding stylus. The local soft grains thus tended to participate strongly on the ploughed material formed in front of the indenter. It may be important when assessing the shearing of the ploughed material during abrasion, to address what are the possible mechanisms by which twinning could lessen the localization of slip to delay or even prevent the initiation of cutting and micro-ploughing like wear micro-mechanisms in abrasion. This is however beyond the scope of this study and a topic for further work.

\section{Discussion}

\subsection{Micromechanical approach to tribological contacts}

A large effort is placed on the modeling of tribological contacts such as abrasion in order to understand the complexity of contact loads or formation of wear particles. Hard-particle high-stress abrasion (e.g., by 
(a)

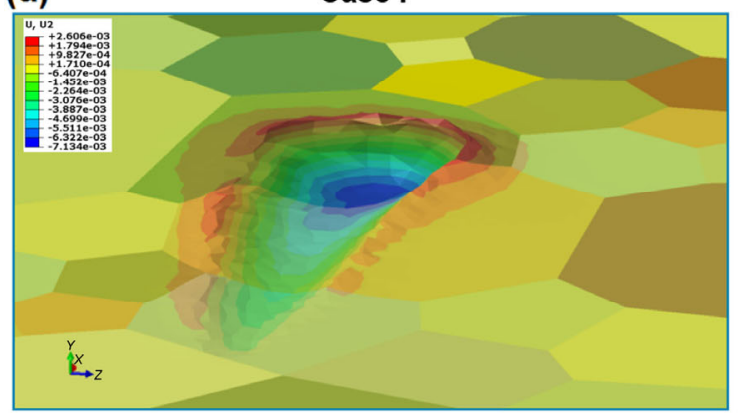

(b)

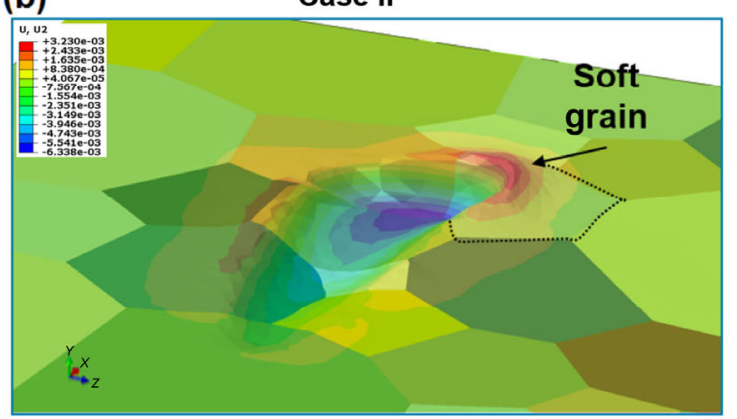

Fig. 6 Surface deformation for (a) case I and (b) case II. Deformation is up-scaled by a factor of 5 for visualization.

natural rocks) provides challenging conditions to many materials including widely used wear-resistant steels. In most cases, however, the models, do not explicitly take microstructure of the material into account, and it is quite difficult to establish any link among microstructural features, such as contact conditions, deformation, hardening, and ultimately wear. The present study focused on the modeling of sliding hard abrasive particle on a polycrystalline material to give a micromechanical perspective on abrasion. The use of crystal plasticity formulation together with a contact model allows including microscale deformation and hardening of a steel material.

Linking local scale deformation phenomena to tribological phenomena can be considered as the main objective and essentially also the novelty in this work. More advanced and refined methodology beyond this work would also allow, for example, establishing a connection between strain localization (e.g., shear band formation) and formation of wear particles in the future through intra-shear band cracking. The phenomenon of localization itself is dependent on the microstructural features of the material and on loading conditions [44]. Among other characteristics, grain morphology and size, orientation distribution, defect population, and general material's capability to withstand deformation and its susceptibility to develop damage are all relevant contributors in a wear process. Discretized descriptions of the microstructure can be performed by directly incorporation of characterization data, such as EBSD measurements of the grain structure and its orientations and local defects. This process involves the generation of a computational domain directly from available 2D or 3D measurement data and its utilization in the simulations of simple deformation or more complex tribological contacts. However, restrictions exist. For example, 2D based models lack the full field description of abrasive contact that takes place in 3D and related triaxial stress states of abrasive or impact loads, making it more representative in terms of microstructural description but simplified in the contact description, as noted by Laukkanen et al. [38]. Advanced characterization techniques can provide a fairly accurate 3D microstructural model, making use of techniques such as focused ion beam (FIB) milling and EBSD reconstruction of the microstructure [45] or 3D tomography imaging [46]. The construction of the model with pre-mentioned techniques is rather expensive (former) or they may lack sufficient resolution of the microstructural details (latter).

Alternatively, the microstructure for computational tribological contacts may be generated by using a synthetic description of the microstructure. It often features extraction of statistical details from the microstructure and generation of the $2 \mathrm{D} / 3 \mathrm{D}$ representative volume element based on the data. The process involves a decrease in the accuracy of the microstructural description, i.e., exact microstructure versus statistically description, but it is a cost-efficient method. In either direct generation of the microstructure based on measurements or using the synthetic method, the most desired aspect is that virtual examination of the microstructure is possible in tribological contacts, such as abrasion. Furthermore, it becomes possible to virtually modify (alter the microstructure) and test different microstructures and their responses. This aims to support and reduce the need for extensive and possibly expensive experimental work, paving the way to virtual materials design. 


\subsection{Microstructure based model for Hadfield steel in abrasion}

The results highlighted that a contacting abrasive particle sliding on the surface of the polycrystalline metal generates a triaxial stress state around the contact. From the 1st principal stress point of view, the stresses can be categorized to compressive and tensile stress states. The results showed that compression prevails in front and under the contact zone and a trailing tensile stress state is observed. Holmberg et al. [29] noticed similar stress distribution for coatings; however, crystal plasticity-based models involve more complex microstructures as well as more detailed deformation mechanisms that also reveal localization stress field.

In general, the stresses are relatively smooth and correspond to continuum contact studies in an average sense. However, local microstructural features such as grain structure affect the stress state, intra-granular, and inter-granular variations are found accompanied by the stress concentrations close to the grain boundaries. Grain structure alone is not responsible for the localization effects, but effectively also the formation of intense and occasionally localized twinning contributed strongly not only to the plastic deformation but also to the hardening that elevates stresses. The importance of this phenomena is that also the subsurface grains exhibit slip banding and twin accumulation before they become in contact with the abrading particles when material wear progresses. The strengthening effect of the twin barriers increases microhardness of the grains notably [25]. Moreover, the ductility of the material is less affected because the twins allow alternative deformation route and arrest the formation of highly localized slip bands, and the loss of ductility takes place only at high strains [3].

A heavily deformed region is developed at the bottom of the scratch (Fig. 3). The cumulative plastic strains are extremely high, e.g., $150 \%$ near the surface. Relatively high plastic strains were found penetrating $50-150 \mu \mathrm{m}$ deep into the material in the present simulations at the scratch bottom. The scratch edge regions that are ploughed during deformation do not exhibit such extreme plasticity but still showed high twin volume fractions. The twins accumulate to very high volume fractions at the bottom of the scratch, such as $0.5-0.85$, while the edge regions usually showed twin propensity of around 0.2-0.35. In both cases, the twin volume fraction is high enough to increase the flow stress and thus hardness of the material. Experimental scratch tests on the Hadfield material has shown that the hardness at the scratch bottom can increase from 250 up to $700 \mathrm{HV}$ [33]. The lower plasticity and twinning at the edge regions are not likely to increase the hardness to such extent. The measurements on the edge region are cumbersome. However, simulations in our previous work show that $0.2-0.3$ twin volume fractions tend to increase the flow stress of the material from 350 to over $1,000 \mathrm{MPa}[19,25]$. The edge regions of the scratch show similar 0.2-0.3 twin volume fractions, which suggests that the edge regions are likely to become markedly stronger than the undeformed base material. It should be noted that the loss of load-carrying capability due to large deformations at the heavily deformed region in the scratch bottom does not immediately occur even at high loads, which was shown in experimental cyclic scratch tests [3, 40]. This means that the material can undergo further plasticity until failure occurs, which, however, is not included in the present modeling approach and thus cannot be represented by the model. Accordingly, the combination of a heavily deformed layer at the scratch bottom and plasticity at the edge pile-up regions is to be considered beneficial to the abrasive resistance of the material.

High-stress abrasion generates residual stresses in the material. The heavily deformed layer close to the surface was shown to remain in residual tension after the sliding indenter has passed, as is observed in Fig. 2. Compressive stresses prevail deeper in the sub-surface of the trailing region of the contact. Given the intensity of the stresses, it is possible that the tensile stresses could initiate damage at the surface, such as a grain boundary opening. Previous characterization effort on the studied material has shown that grain boundary opening is one source of failure in the material [39]. The ploughing in front of the indenter could activate shear cutting of wear particles, but given the ductility of the material, it could be expected to take place only at very large deformations. The shear failure would require a more detailed analysis of the ploughing region with a damage modeling technique, which is one future topic. 
Figure 7 summarizes the experimentally observed phenomena on a field sample used in a mineral jaw crusher together with the current simulation results. The evident heavily deformed tribolayer is observable in both cases. The most extensive deformation restricts to fractions of one grain because of the large grain size of the material, or up to two grains in some cases, when the grain size is smaller. This is visible in both simulation cases and field tests. It can be seen from Fig. 7(a) that beyond heavily deformed tribolayer, the deformation twins spread deep into the material, up to several millimeters. The twins are likely formed during cyclic high stress abrasive and high energy impact loadings provided by continuous rock crushing and feed action. Although the simulations restrict to only one aggressive abrasive contact, the number of active twin systems in Fig. 7(d) shows that microtwinning is observed up to several grains deep into the material. The numerical results show that these are to be considered as microtwins because the local twin volume fraction is not high, but the twins have nucleated. One important aspect is that the hardening effect of microtwins is to be considered remarkable $[10,47]$ because of the dense spacing of thin twin bands, that are dynamically growing barriers for dislocations. In addition, the number of active twin systems is high from 3 to 6 usually, making it more probable that they can act as non-coplanar barriers for dislocations and other twin systems. Subsequent contacts are very likely to increase the subsurface deformation and cause gradient hardening effect seen in Fig. 7(c).

Investigation of special loading cases is possible with the present micromechanical approach. For example, it was shown by the present study that the material can exhibit deformation twinning in abrasive conditions, while simple uniaxial compression or tension tests would indicate that twinning is suppressed in certain orientations [15]. The contact conditions induce triaxial stress state that triggers twinning in spite of the prevailing principal stress state being compression or tension. From the materials design point of view, the present technique allows taking a new approach. Different grain structures could be investigated, for example against different abrasives or abrasive sizes. Furthermore, alloy design has a key role when promoting deformation twinning or biasing to alternative deformation mechanisms such as martensitic transformation $[48,49]$, when for example seeking improvements for abrasion resistance. Given the complexity of the contact conditions and its relationship to microscale features and deformation, modeling of abrasion with a microstructure model utilizing crystal plasticity is a valid and valuable tool. Including damage mechanisms within the crystal plasticity formulation is possible [50,51], and it could provide additional information about the failure process

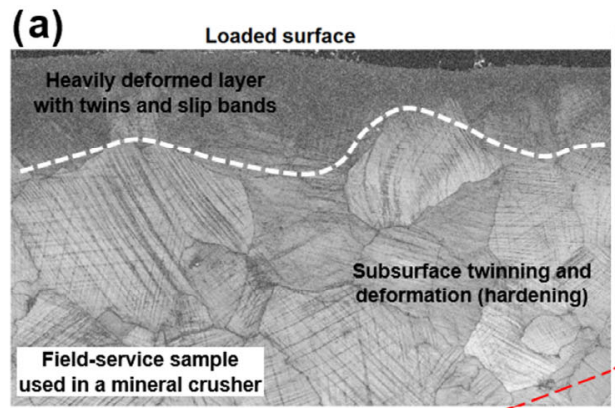

(d)

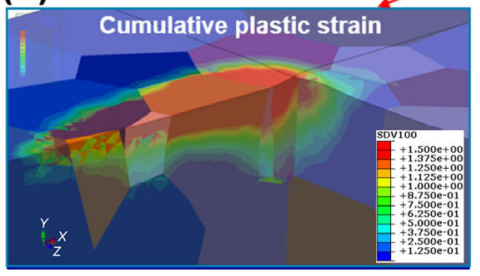

(e) (b)
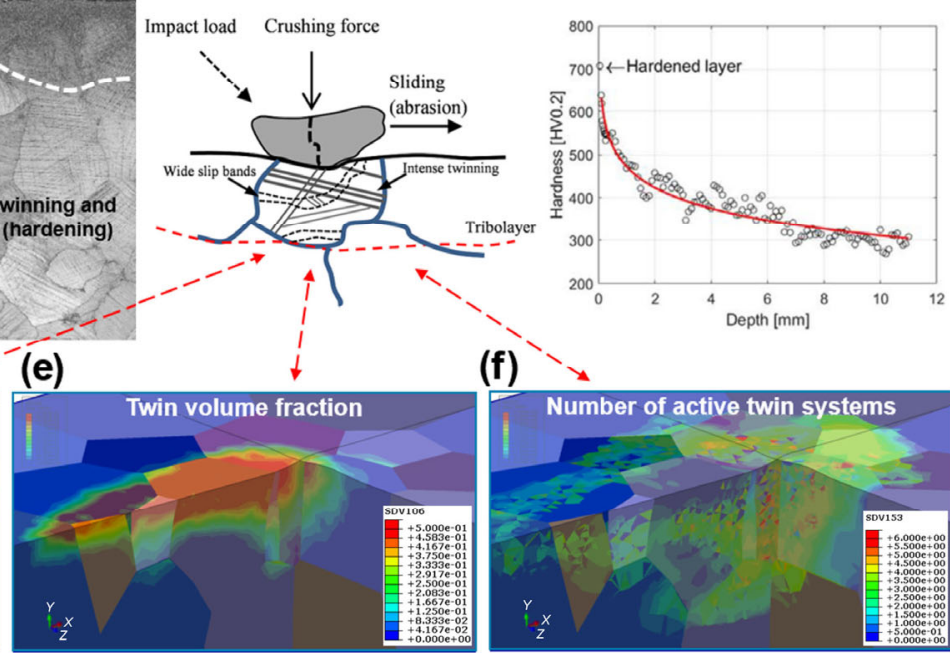

(c)

(f)

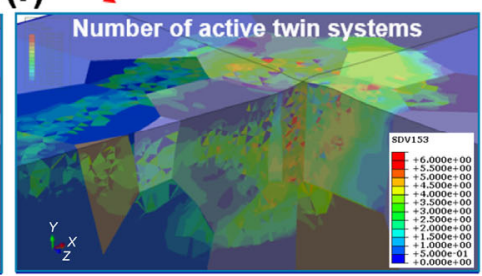

Fig. 7 (a) Cross-section of field-service sample, (b) schematic of surface deformation, (c) cross-section hardness gradient, reproduced from [36], (d) cumulative plastic strain (red color is 0.8 ), (e) twin volume fraction (red is 0.5 ), and (f) number of currently active twin systems (red is 6). 
leading to the formation of wear particles, and it should be considered in future scopes of micromechanical modeling of tribological contacts. Ultimately, a full field process-structure-properties-performance mapping is possible, but achievable only after each aspect of the material's virtual development phase is considered and sufficiently understood. In the scope of Hadfield steels, the design of novel alloys would require a rather sophisticated coupling of the micromechanical model to process models, such as phasefield or cellular automata model(s) that can predict the formation of the microstructure as well as the segregation of solutes and susceptibility to the formation of defects (e.g., carbides). Furthermore, a thermodynamical approach is inevitably a necessity to evaluate material's stacking fault energy that has a great influence on the propensity of twinning and susceptibility to martensitic transformation.

\section{Conclusions}

The micromechanical approach was employed to numerically study single contact abrasion on a high manganese austenitic steel. Crystal plasticity framework was utilized and the microstructure of the material was included in the abrasion model. The following conclusions and observations can be made:

(1) Micromechanically inspired modeling approach allows to investigate the local effects of microstructure, link deformation mechanisms and hardening to the material's behavior under abrasive contact, demonstrating the wide possibilities of the technique.

(2) A heavily deformed and hardened "tribolayer" is formed close to the surface already during the first aggressive scratch. Both intense local slip deformation and dense twin formation are responsible for the strong hardening exhibited by the material inside and around the scratch zones. Similar observations can be made in experiments and simulations.

(3) The grain structure and their orientations affect the formation of twins at the surface as well as in the subsurface of the material. High-stress abrasion induces microtwinning deep into the material, up to several grains deep red. The pre-existing subsurface hardening improves the material's resistance against deformation while remaining sufficiently ductile, and therefore likely improves abrasive resistance of the Hadfield material by this mechanism when the surface layers dynamically wear off by ductile failure mechanisms and grain boundary separation.

(4) Intense twinning takes place at the scratch bottom and moderate twinning is induced at the ploughed scratch edges. Ploughing in front of the sliding particle introduces plasticity including twinning in the ploughed region. The main contribution to deformation twinning occurs during the compressive loading stage of the sliding particle, in front and on (under) the contact site. Additional increase in twin volume fraction is occasionally observed at the trailing edge of the contact, which depends on the grain orientation and its relationship to activation of twin systems, and the pre-existing twin volume fraction on other twin systems that has suppressing effect on twin activity.

(5) Tension-compression asymmetry of Hadfield steels, susceptible for deformation twinning, is reduced by the complex triaxial stress state of abrasive contacts.

Open Access This article is licensed under a Creative Commons Attribution 4.0 International License, which permits use, sharing, adaptation, distribution and reproduction in any medium or format, as long as you give appropriate credit to the original author(s) and the source, provide a link to the Creative Commons licence, and indicate if changes were made.

The images or other third party material in this article are included in the article's Creative Commons licence, unless indicated otherwise in a credit line to the material. If material is not included in the article's Creative Commons licence and your intended use is not permitted by statutory regulation or exceeds the permitted use, you will need to obtain permission directly from the copyright holder.

To view a copy of this licence, visit http://creativecommons.org/licenses/by/4.0/.

\section{References}

[1] Lencina R, Caletti C, Brunelli K, Micone R. Assessing wear performance of two high-carbon Hadfield steels through field tests in the mining industry. Proced Mater Sci 9: 358-366 (2015)

[2] Lindqvist M, Evertsson C M. Liner wear in jaw crushers. 
Miner Eng 16(1): 1-12 (2003)

[3] Lindroos M, Apostol M, Heino V, Valtonen K, Laukkanen A, Holmberg K, Kuokkala V T. The deformation, strain hardening, and wear behavior of chromium-alloyed Hadfield steel in abrasive and impact conditions. Tribol Lett 57(3): 24 (2015)

[4] Sinha R, Mukhopadhyay A K. Wear characterization and modelling of Mn-steel liners used in rock crushers. Perspect Sci 8: 374-376 (2016)

[5] Terva J, Kuokkala V T, Valtonen K, Siitonen P. Effects of compression and sliding on the wear and energy consumption in mineral crushing. Wear 398-399: 116-126 (2018)

[6] Canadinc D, Sehitoglu H, Maier H J, Chumlyakov Y I. Strain hardening behavior of aluminum alloyed Hadfield steel single crystals. Acta Mater 53(6): 1831-1842 (2005)

[7] Canadinc D, Sehitoglu H, Maier H J, Niklasch D, Chumlyakov Y I. Orientation evolution in Hadfield steel single crystals under combined slip and twinning. Int J Solids Struct 44(1): 34-50 (2007)

[8] Dastur Y, Leslie W. Mechanism of work hardening in Hadfield manganese steel. Metall Trans A 12(5): 749-759 (1981)

[9] Hutchinson B, Ridley N. On dislocation accumulation and work hardening in Hadfield steel. Scr Mater 55(4): 299-302 (2006)

[10] Onal O, Ozmenci C, Canadinc D. Multi-scale modeling of the impact response of a strain-rate sensitive high-manganese austenitic steel. Front Mater 1: 16 (2014)

[11] Bayraktar E, Levaillant C, Altintas S. Strain rate and temperature effect on the deformation behavior of the original Hadfield steel. J Phys IV 3: C7 61-66 (1993)

[12] Canadinc D, Efstathiou C, Sehitoglu H. On the negative strain rate sensitivity of Hadfield steel. Scr Mater 59: 11031106 (2008)

[13] Adler P H, Olson G B, Owen W S. Strain hardening of Hadfield manganese steel. Metall Mater Trans A 17(10): 1725-1737 (1986)

[14] Idrissi H, Renard K, Ryelandt L, Schryvers D, Jacques P J. On the mechanism of twin formation in Fe-Mn-C TWIP steels. Acta Mater 58(7): 2464-2476 (2010)

[15] Karaman I, Sehitoglu H, Gall K, Chumlyakov Y I, Maier H J. Deformation of single crystal Hadfield steel by twinning and slip. Acta Mater 48(6): 1345-1359 (2000)

[16] Owen W S, Grujicic M. Strain aging of austenitic Hadfield manganese steel. Acta Mater 47(1): 111-126 (1998)

[17] Zuidema B K, Subramanyam D, Leslie W C. The effect of aluminum on the work hardening and wear resistance of Hadfield manganese steel. Metall Mater Trans A 18(9): 1629-1639 (1987)

[18] Karaman I, Sehitoglu H, Beaudoin A J, Chumlyakov Y I,
Maier H J, Tomé C N. Modeling the deformation behavior of hadfield steel single and polycrystals due to twinning and slip. Acta Mater 48(9): 2031-2047 (2000)

[19] Lindroos M, Cailletaud G, Laukkanen A, Kuokkala V T. Crystal plasticity modeling and characterization of the deformation twinning and strain hardening in Hadfield steels. Mater Sci Eng A 720: 145-159 (2018)

[20] Lindroos M, Laukkanen A, Cailletaud G, Kuokkala V T. On the effect of deformation twinning and microstructure to strain hardening of high manganese austenitic steel 3D microstructure aggregates at large strains. Int J Solids Struct 125: $68-76$ (2017)

[21] Canadinc D, Sehitoglu H, Karaman I, Chumlyakov Y, Maier $\mathrm{H}$. The role of nitrogen on the deformation response of Hadfield steel single crystals. Metall Mater Trans A 34(9): 1821-1831 (2003)

[22] Toker S M, Canadinc D, Taube A, Gerstein G, Maier H J. On the role of slip-twin interactions on the impact behavior of high-manganese austenitic steels. Mater Sci Eng A 593: 120-126 (2014)

[23] Gumus B, Bal B, Gerstein G, Canadinc D, Maier H J. Twinning activity in high-manganese austenitic steels under high velocity loading. Mater Sci Technol 32(5): 463-465 (2015)

[24] Gumus B, Bal B, Gerstein G, Canadinc D, Maier H J, Guner F, Elmadagli M. Twinning activities in high-Mn austenitic steels under high-velocity compressive loading. Mater Sci Eng 648: 104-112 (2015)

[25] Lindroos M, Laukkanen A, Cailletaud G, Kuokkala V T. Microstructure based modeling of the strain rate history effect in wear resistant Hadfield steels. Wear 396-397: 56-66 (2018)

[26] Bal B, Gumus B, Canadinc D. Incorporation of dynamic strain aging into a viscoplastic self-consistent model for predicting the negative strain rate sensitivity of Hadfield steel. J Eng Mater Technol, 138(3): 031012

[27] Biyikli E, Toker S M, Canadinc D. Incorporating the grain boundary misorientation effects on slip activity into crystal plasticity. Mech Adv Mater Struct 23(8): 865-872 (2016)

[28] Mirzajanzadeh M, Canadinc D. A microstructure-sensitive model for simulating the impact response of a high-manganese austenitic steel. J Eng Mater Technol 138(4): 041004 (2016)

[29] Holmberg K, Laukkanen A, Ronkainen H, Wallin K, Varjus $\mathrm{S}$, Koskinen J. Tribological contact analysis of a rigid ball sliding on a hard coated surface: Part I: Modelling stresses and strains. Surf Coat Technol 200(12-13): 3793-3809 (2006)

[30] Holmberg K, Laukkanen A, Turunen E, Laitinen T. Wear resistance optimisation of composite coatings by computational microstructural modelling. Surf Coat Technol 247: 1-13 (2014) 
[31] Laukkanen A, Lindroos M, Andersson T, Verho T, Pinomaa T. Micromechanical modeling of failure behavior of metallic materials. Rakent Mek 50(3): 271-274 (2017)

[32] Sabnis P A, Forest S, Arakere N K, Yastrebov V A. Crystal plasticity analysis of cylindrical indentation on a Ni-base single crystal superalloy. Int J Plast 51: 200-217 (2013)

[33] Gao Y F, Larson B C, Lee J H, Nicola L, Tischler J Z, Pharr G M. Lattice rotation patterns and strain gradient effects in face-centered-cubic single crystals under spherical indentation. J Appl Mech 82: 061007 (2015)

[34] Nicola L, Bower A F, Kim K S, Needleman A, van der Giessen E. Multi-asperity contact: A comparison between discrete dislocation and crystal plasticity predictions. Philos Mag 88(30-32): 3713-3729 (2008)

[35] Musinski W D, McDowell D L. On the eigenstrain application of shot-peened residual stresses within a crystal plasticity framework: Application to Ni-base superalloy specimens. Int J Mech Sci 100: 195-208 (2015)

[36] Rousseau T, Nouguier-Lehon C, Gilles P, Hoc T. Finite element multi-impact simulations using a crystal plasticity law based on dislocation dynamics. Int J Plast 101: 42-57 (2018)

[37] Durand J, Proudhon H, Cailletaud G. Contact between rough surfaces: Crystal plasticity influence on the contact tightness estimation. Blucher Mech Eng Proc 1(1): 1-12 (2014)

[38] Laukkanen A, Holmberg K, Ronkainen H, Stachowiak G, Podsiadlo P, Wolski M, Gee M, Gachot C, Li L. Topographical orientation effects on surface stresses influencing on wear in sliding DLC contacts, part 2: Modelling and simulations. Wear 388-389: 18-28 (2017)

[39] Lindroos M. Experimental and numerical studies on the abrasive and impact behavior of wear resistant steels. Ph.D. Thesis. Tampere (Finland): Tampere University of Technology, 2016.

[40] Lindroos M, Valtonen K, Kemppainen A, Laukkanen A, Holmberg K, Kuokkala V T. Wear behavior and work hardening of high strength steels in high stress abrasion. Wear 322-323: 32-40 (2015)

[41] Franciosi P. The concepts of latent hardening and strain

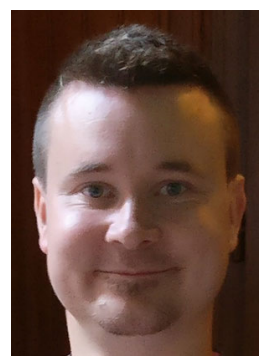

Matti LINDROOS. He currently holds a position of senior scientist at VTT Technical Research Centre of Finland Ltd., focusing on multiscale materials modeling and integrated computational materials engineering. hardening in metallic singlecrystals. Acta Metall 33(9): 1601-1612 (1985)

[42] Kalidindi S R. Modeling anisotropic strain hardening and deformation textures in low stacking fault energy FCC metals. Int J Plast 17: 837-860 (2001)

[43] Salem A A, Kalidindi S R, Semiatin S L. Strain hardening due to deformation twinning in $\alpha$-titanium: Constitutive relations and crystal-plasticity modeling. Acta Mater 53(12): 3495-3502 (2005)

[44] Lindroos M, Laukkanen A, Kuokkala V T. A crystal plasticity approach for shear banding in hot rolled high-strength steels. Metall Mater Trans A 48(11): 5608-5615 (2017)

[45] Mingard K P, Jones H G, Gee M G. Metrological challenges for reconstruction of 3-D microstructures by focused ion beam tomography methods. J Microsc 253(2): 93-108 (2014)

[46] Ludwig W, King A, Reischig P, Herbig M, Lauridsen E M, Schmidt S, Proudhon H, Forest S, Cloetens P, du Roscoat $\mathrm{S} R$, et al. New opportunities for $3 \mathrm{~d}$ materials science of polycrystalline materials at the micrometre lengthscale by combined use of X-ray diffraction and X-ray imaging. Mater Sci Eng 524(1-2): 69-76 (2009)

[47] Efstathiou C, Sehitoglu H. Strain hardening and heterogeneous deformation during twinning in Hadfield steel. Acta Mater 58(5): 1479-1488 (2010)

[48] Chen H, Zhao D, Wang Q L, Qiang Y H, Qi J W. Effects of impact energy on the wear resistance and work hardening mechanism of medium manganese austenitic steel. Friction 5(4): 447-454 (2017)

[49] Wong S L, Madivala M, Prahl U, Roters F, Raabe D. A crystal plasticity model for twinning- and transformationinduced plasticity. Acta Mater 118: 140-151 (2016)

[50] Sabnis P A, Forest S, Cormier J. Microdamage modelling of crack initiation and propagation in FCC single crystals under complex loading conditions. Int J Eng Sci 312: 468-491 (2016)

[51] Aslan O, Cordero N M, Gaubert A, Forest S. Micromorphic approach to single crystal plasticity and damage. Int J Eng Sci, 49(12): 1311-1325 (2011)

His research interests include tribology and wear, solid mechanics, micromechanical materials behavior, plasticity and fracture mechanisms across scales and all materials, and virtual design of new material solutions. He got his M.S. and Ph.D. degrees from Tampere University of Technology, Finland. 


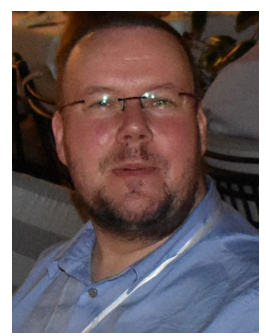

Anssi LAUKKANEN. $\mathrm{He}$ is a principal scientist at VTT Technical Research Centre of Finland Ltd., responsible for the development of integrated computational materials engineering solutions employing multiscale and multiphysics modeling. At VTT, he is the responsible principal investigator for computational material sciences and engineering, the associated strategic scientific spearhead,

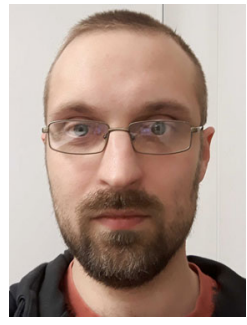

Tom ANDERSSON. He is a senior scientist at VTT Technical Research Centre of Finland Ltd. His research interests include mechanics of materials and numerical analysis in and leading the affiliated research group activities. His research interests include development of multiscale modeling techniques especially in the micromechanical range, consisting of modeling of single and polycrystal scale phenomena affiliated with deformation and failure behavior of materials. He got his M.S. degree from Helsinki University of Technology, Finland, and Ph.D. degree from Tampere University of Technology, Finland, in materials science.

the micromechanical range focusing on deformation and failure behavior of materials. He got his M.S. degree from Helsinki University of Technology, Finland, in materials science. 